\title{
JUSTICE OR JUST BETWEEN US? EMPIRICAL EVIDENCE OF THE TRADE-OFF BETWEEN PROCEDURAL AND INTERACTIONAL JUSTICE IN WORKPLACE DISPUTE RESOLUTION
}

\author{
ZEV J. EIGEN AND ADAM SETH LITWIN*
}

\begin{abstract}
In this article, the authors examine the relationship between an employer's implementation of a typical dispute resolution system (DRS) and organizational justice, perceived compliance with the law, and organizational commitment. They draw on unique data from a single, geographically expansive, U.S. firm with more than 100,000 employees in more than 1,000 locations. Holding all timeconstant, location-level variables in place, they find that the introduction of a DRS is associated with elevated perceptions of interactional justice but diminished perceptions of procedural justice. They also find no discernible effect on organizational commitment, but a significant boost to perceived legal compliance by the company. The authors draw on these findings to offer a "differentialeffects" model for conceptualizing the relationship among organizational justice, perceived legal compliance, and the implementation of dispute resolution mechanisms.
\end{abstract}

$\mathrm{I}^{-1}$ n this article, we examine the effects of implementation of a typical workplace dispute resolution system (DRS) on employees covered by the DRS, the vast majority of whom are never claimants or participants in a claim submitted through the DRS. This inquiry is made possible by access to a unique set of survey data from a large national company that, at its peak, employed more than 100,000 workers in more than 1,000 locations. The employer implemented the DRS, described in more detail below, in the middle of the eight-year span of the study, enabling a rare glimpse into

\footnotetext{
*Author names are in alphabetical order. Zev J. Eigen is an Associate Professor of Law at Northwestern University School of Law. Adam Seth Litwin is an Assistant Professor at the Carey Business School at Johns Hopkins University and a research affiliate of the Employment Policy Research Network. The authors acknowledge the generosity of "Gilda's, Inc." and, more specifically, of managers in its Human Resources Department for their assistance and patience. The authors also thank Kenneth Ayotte, Mariano-Florentino Cuéllar, Sam Estreicher, John-Paul Ferguson, Roberto Fernandez, Thomas A. Kochan, David Lewin, and the participants of Northwestern University School of Law's Internal Faculty Workshop, University of Southern California Law School's Faculty Workshop, and MIT's IWER seminar for their helpful guidance and suggestions. While the authors' agreement with the focal firm prevents them from sharing the raw data, copies of the computer programs used to generate the results are available from the first author at z-eigen@northwestern.edu.
} 
pre- and post-implementation perceptions of justice, organizational commitment, and the degree to which employees believe the company is complying with employment laws. We rely on these data and qualitative data collected from individuals working for the employer over a two-year period to present a case in which extant theory fails to explain observed outcomes. Specifically, theory predicts that implementation of a workplace DRS should improve employees' perceptions of procedural justice, but our findings suggest quite the opposite. Theory predicts that employees' procedural justice perceptions and interactional justice perceptions should be harmonious. Our results present evidence that this does not have to be so. Implementation of the DRS in the data studied corresponded with improved perceived interactional justice and perceived legal compliance, suggesting a potential trade-off in effects associated with the DRS that was not previously conceptualized or documented. From this we advance a new conceptual model of the relationship among DRS implementation, organizational justice, and perceived legal compliance. We first offer some background on the existing scholarship examining organizational justice and the connection between it and workplace outcomes and behaviors. We then detail the methods, data, and results of the present study. We do this by explaining why DRS implementation is thought to increase procedural justice, which in turn, increases organizational trust, and then leads to positive outcomes associated with improved organizational commitment. This proves important to understanding our framework as well as the results we report.

\section{Background}

\section{Organizational Justice}

Organizational justice is the measure of how fairly employees feel treated at work in terms of outcomes and processes. Justice is commonly subclassified into three distinct subcategories: distributive, procedural, and interactional (Cohen-Charash and Spector 2001; Colquitt et al. 2001; Cropanzano, Prehar, and Chen 2002). Distributive justice gauges fairness or equity of outcomes or rewards (Folger 1977). Procedural justice gauges fairness of processes (Thibaut and Walker 1975; Lind and Tyler 1988). Interactional justice measures the perceived fairness of interpersonal treatment (Bies and Moag 1986). Scholarship suggests that the more fairly employees feel they are treated, the more likely they are to be committed to the organization (Hubbell and Chory-Assad 2005) and to display what is often referred to as "organizational citizenship behavior" (Moorman 1991; Moorman, Niehoff, and Organ 1993; Niehoff and Moorman 1993). This behavior includes things like improved productivity, performance, and related measures (Greenberg and Barling 1996). Organizational commitment may also be measured in terms of reduced turnover (Spencer 1986; Byrne 2005). Conversely, when employees feel that their employers treat them unfairly in terms of decisionmaking or outcomes, employees are more likely to feel less committed to the 
organization, are more likely to exit the firm, and are more likely to enact counterproductive work behaviors such as shirking, theft, or neglect of duty (Greenberg 1990; Sheppard, Lewicki, and Minton 1992; Folger 1993; Greenberg 1993; Cohen-Charash and Spector 2001). While researchers have studied all three subcategories of organizational justice, procedural justice is thought to be most important in understanding employee reactions to managerial policies and decision-making (Naumann and Bennett 2000; Colquitt 2001; Colquitt et al. 2001). In short, more than four decades of research suggests two things. First, it is important to measure under what circumstances and to what degree employees feel they are fairly treated at work in terms of all three varieties of organizational justice, but perhaps most important with respect to procedural justice. Second, employees' perceptions of how fairly they are treated at work correlates with behaviors and outcomes of deep concern to policymakers, politicians, union organizers, employers, researchers, and anyone else generally concerned with workplace governance, efficiency, productivity, and stability.

\section{Justice and Workplace Dispute Resolution}

One of the most critical ways of assessing organizational justice is by evaluating how organizations address disputes (Lewin 1987; Boroff 1991; Colvin, Klaas, and Mahony 2006; Blancero, DelCampo, and Marron 2010). Improved perceived legitimate opportunities for voice and greater perceived access to procedurally fair and neutral processes for resolving disputes should increase employees' organizational commitment and decrease turnover, consistent with the "exit-voice-loyalty" trade-off (Hirschman 1970; Folger 1977; McCabe and Lewin 1992). Resolving conflict internally also reduces costs because litigating disputes is often more expensive than addressing them internally (Estreicher and Eigen 2010). Greater perceived organizational justice (particularly procedural justice) has been shown to correlate with less employee complaining about legal issues and less external resorts to law (Wallace, Edwards, Mondore, and Finch 2008). Along these lines, internal DRSs reduce the likelihood that what might otherwise be a lower-cost nonlegal issue (e.g., an employee complaint of generic unfair treatment) gets transmogrified by a plaintiff lawyer into a higher-cost legal issue (e.g., alleging that the unfair treatment was a manifestation of employment discrimination). Private mediation and arbitration have been shown to result in high levels of participant satisfaction (Lipsky, Seeber, and Fincher 2003; Lipsky and Seeber 2006). A substantial body of literature suggests that increased participation in dispute resolution processes increases the likelihood that claimants will regard their claims as justly addressed. The standard model predicts that if employees regard the DRS as procedurally just, they will use it to resolve both legal and nonlegal issues, be happier, be less likely to exit the firm, and be more committed to the organization. Less clear is if, whether, and to what extent, employees regard the implementation or general availability of a workplace DRS as a fair action taken 
by the employer when those employees are not claimants or participants in claims addressed by the DRS.

All three subcategories of organizational justice may be useful for assessing the overall fairness of employer-implemented policies or programs such as a dispute resolution system, but research has suggested that procedural justice is the most useful and likely the most salient (Konovsky and Folger 1991). Some have suggested that while distributive justice is useful for predicting personal-level evaluations (such as pay satisfaction or outcomes of specific disputes in which an individual was the claimant), procedural justice is perhaps the most useful metric for understanding organizational-level evaluations (like organizational commitment) (McFarlin and Sweeney 1992; Sweeney and McFarlin 1993). Procedural justice has been the focus of many studies of employer policies such as DRSs. For the purposes of evaluating DRSs, it seems that comfort with initiating claims and the perception that the DRS will address the claim in a neutral, effective, and fair way are the two most critical elements by which to gauge the success or failure of a DRS, at least as measured from the employer's perspective (Folger and Bies 1989; Tyler and Bies 1990; Sheppard, Lewicki, and Minton 1992). The consensus reached by prior scholarship is that procedural justice matters, is distinct from the other types of organizational justice, and is more likely to influence overall fairness judgments than distributive justice (Konovsky and Folger 1991; Greenberg and Cropanzano 2001).

Prior research theorizes and predicts a positive correlation between DRS implementation and improved procedural justice perceptions among employees (Thibaut and Walker 1975; Tyler 1988; Tyler and Bies 1990; Colvin 2003; Blancero, DelCampo, and Marron 2010). Some, however, believe this is true only in union environments, or when a high degree of organizational trust is present. Theorists disagree on whether improved perceived procedural justice is even attainable in a nonunionized setting in which a DRS is unilaterally imposed by an employer as opposed to being the product of collective bargaining. In such circumstances, employee participation is necessarily less collective and more individualized (Clegg 1975; Sheppard, Lewicki, and Minton 1992; Budd 2004). More speculation and hypothesizing than empirical study has transpired regarding the relationship between procedural justice and DRS implementation in the nonunion setting. The paucity of research may be due in part to the private nature of employment dispute resolution and the difficulty of gaining access to data. To the extent that information is reported through clearinghouses such as the American Arbitration Association (AAA), it may be reasonably assumed that AAA data capture only the tip of the iceberg, may not be representative of non-available data, and most important for this study, never include any information about how employees perceive workplace metrics related to organizational justice before implementation of a workplace DRS. Research has focused on discerning the characteristics of competing dispute resolution models (Ewing 1989), the causes for grievance initiation (Boroff and Lewin 1997), the effects of grievance activity (Ichniowski 1986), claimant win rates (Sherwyn, 
Estreicher, and Heise 2005; Colvin 2011), disputants' perceptions of procedural justice (Aram and Salipante 1981; Fryxell and Gordon 1989), and postgrievance outcomes for claimants (Lewin 1987; Lewin and Peterson 1999) among other important aspects of employment dispute resolution. However, very little is known about the effects of DRS implementation on non-claimant and non-participant employees in the nonunion private sector.

As others have observed, in stark contrast to procedural justice, interactional (or interactive) justice is the most understudied component of organizational justice (Hubbell and Chory-Assad 2005). In spite of this, it is expected to be an important component of organizational justice and related most closely to how employees perceive their supervisors (Tyler and Blader 2000). Interactional justice is distinct from procedural justice. It measures the extent to which employees believe their needs are taken into account in making decisions and the extent to which employees are provided with adequate explanations when decisions are finalized (Bies and Moag 1986; Aquino, Lewis, and Bradfield 1999; Masterson, Lewis, Goldman, and Taylor 2000; Bies 2001). While these issues have been examined carefully, sometimes even in the context of managerial trust and related concepts, few, if any, attempts have been made to understand the interrelationship among interactional justice, procedural justice, and DRS implementation. One study by Hubbell and Chory-Assad (2005) explored the relationship between procedural and interactional justice and managerial and organizational trust. They found that procedural justice is the strongest predictor of both organizational and managerial trust, distributive justice predicts only managerial trust, and interactional justice does not predict either type of trust. Their study, however, was not examining an employer with any DRS in place.

The quality of the interpersonal treatment that an aggrieved employee receives from the decision maker and the way in which the decision maker enacts the formal procedure will heavily influence the aggrieved party's perceptions of whether the procedures are fair (Tyler and Bies 1988; Tyler and Blader 2000). Honesty, courtesy, respectfulness, and appropriate professional decorum affect the way employees regard the fairness of procedures implemented (Sheppard, Lewicki, and Minton 1992). Niehoff and Moorman (1993) developed a nine-item, validated measure of interactional justice that gauges employees' beliefs about their managers' interest in their opinions in work-related issues and how much their managers treat them with courtesy and respect, among other related factors. Other variations come into play on this measure, but for the most part, assessments of interactional justice cover the same ground.

\section{The Standard Model of DRS Implementation, Organizational Justice, and Commitment}

Figure 1 depicts the standard model connecting DRS implementation, procedural justice, and organizational commitment as theoretically and empirically described in the literature. As organizational trust features in past 
Figure 1. Standard Model Connecting DRS Implementation, Procedural Justice, and Organizational Commitment

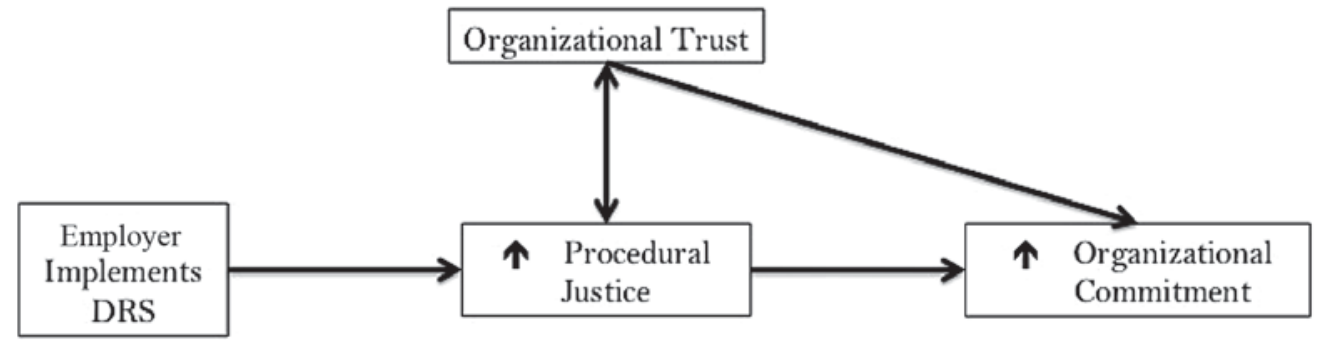

work on these constructs, it is worth briefly explaining how it fits in here. Organizational trust has been described as a "feeling of confidence and support in an employer," and the belief that the employer will follow through on commitments (Gilbert and Li-Ping 1998). It is commonly conceptualized as a product of organizational justice (Folger and Konovsky 1989; Whitener 2001; Cropanzano, Prehar, and Chen 2002; Ambrose and Schminke 2003). The logic of this concept might be cast as follows: If an employer treats an employee fairly, that employee is more likely to trust the employer. Organizational trust may also be the antecedent of organizational justice. The logic of this could be cast as follows: If an employer is trustworthy, the employee is more likely to regard the employer's treatment as fair. This approach is plausible because of asymmetric information in most employment relationships. Employees often lack sufficient baseline information to which they may compare decisions employers render, which makes it more likely that employees will rely on trust in assessing whether alternatives to an observed decision are less favorable than a single observable result. Therefore, as suggested by other researchers, bi-directionality is likely to exist between organizational trust and organizational justice (Colvin, Klaas, and Mahony 2006). To accord this bidirectionality, in Figure 1, organizational trust is shown with double-headed arrows connecting to procedural justice. Organizational trust has been demonstrated to be positively correlated with organizational commitment (Ruppel and Harrington 2000; Whitener 2001), so this is also shown in Figure 1. Traditionally, improved procedural justice perceptions associated with opportunities for employee voice in the form of dispute resolution systems correspond with greater employee retention and organizational commitment.

\section{The Differential Effects Model}

In this article, we suggest a reassessment of the relationship among the important constructs discussed above. We first note that many DRSs, like the one examined in this study, consist of multiple steps beginning with reporting to local managers and culminating in final, binding arbitration (Estreicher and Eigen 2010). Other research has suggested that it makes sense to pay attention to the possible differences in judgments about justice that could come from formal versus informal DRS components. For instance, 
Tyler and Blader (2000) noted that judgments about justice may be characterized differently for perceptions that come from observing formal rules versus observing informal actions by authorities. DRSs often consist of components relating to perceptions about how fair the organization is (the more formal components of the DRS) and components relating to perceptions of how fair local managers are (the less formal components of the DRS). It therefore makes sense to account for this bifurcation when conceptualizing a model describing the effects of DRS implementation. Building on concepts emergent from the literature and grounded in the empirical analysis presented herein, we have done just this. Our model suggests that the act of implementing a DRS with both informal and formal components creates a set of trade-offs. Instead of a unidirectional, universal effect stemming from DRS implementation to increased perceived procedural justice to increased organizational commitment, we theorize that DRS implementation may instead be associated with differential effects that simultaneously increase one form of organizational justice (interactional) while diminishing another form of organizational justice (procedural). Local managers charged with implementing the DRS and explaining it to their employees are incentivized to act in ways that bolster their perceived trustworthiness and fairness as an alternative to resorting to the company's newly implemented formal internal process. Indeed, Colvin's (2004) qualitative analysis of a nonunion dispute resolution system, much like the one under study here, revealed behavioral changes along these lines on the part of managers. After all, local managers do not want to be regarded as failing to handle disputes arising at their locations, and claims that they fail to manage end up being resolved by the DRS's centrally administered formal componentry. Abundant claim escalation might be perceived as suggesting that local managers are doing something personally wrong. So, local managers likely do what they can to increase interactional justice perceptions among their employees in order to decrease the likelihood of employees resorting to the more formal components of the DRS. One result of this structural disincentivization for local managers to champion the formal components of the DRS as procedurally fair could be diminished procedural justice as perceived by employees. In other words, because local managers are the gatekeepers of the DRS, implementation of a DRS could yield increased perceived interactional justice at the expense of diminished perceived procedural justice. Applying existing research and theory, if our differential effects model of organizational justice holds and DRS implementation is associated with an increase in interpersonal justice, there should be a corresponding increase in interpersonal commitment. The simultaneous diminished perceptions of procedural justice should have no effect (or a net negative effect) on organizational commitment. ${ }^{1}$

\footnotetext{
${ }^{1}$ Our differential effects model is only partially tested by the data described below; we do not have the ability to test whether the connection between interpersonal justice and interpersonal commitment exists.
} 


\section{Perceived Legal Compliance}

Aside from this potential differential effect on organizational justice, we suggest examining the connection between DRS implementation and perceived legal compliance by the organization. The connection between justice and legal compliance is well established in other contexts but is relatively understudied in the organizational justice literature (Bies and Tyler 1993; Tyler 2006). Local managers and employees could regard the company's newly implemented process as being established to protect the company's interests. Because local managers do not want to be perceived as failing to dam the tide of disputes that percolate up from their locations (Colvin 2004), the very act of implementing a DRS at a national organization might have the effect of setting the stage for local managers to step to the side of their employees in fostering their trust, and creating an "us versus them" mentality. The "us" includes managers and employees together. The "them" becomes more saliently the amorphous corporate entity implementing the formal DRS apparatus. This sets the stage for implementation of the DRS to be associated with an increase in the degree to which employees perceive that the company is complying with the law.

Perceived legal compliance is an often overlooked but critical component of procedural justice (Tyler 1988; Gopinath and Becker 2000). We suggest that perceived legal compliance may not positively correlate with procedural justice in the context of DRS implementation in a nonunion workplace. Employees may regard implementation of a workplace DRS as a signal that their employer is more likely in compliance with state and federal laws because the employer cares about legal issues and wants to address them. If employees regard DRS implementation as providing a fair benefit above and beyond the set of legal protections and rights to which they feel entitled under the status quo, then perceived legal compliance and procedural justice should both increase with DRS implementation. Alternatively, however, employees could fundamentally distrust their employer. They would regard DRS implementation as a signal that the employer is protecting its interests and taking precautions to avoid liability. In this case, employees would distinguish between an employer protecting its interests by complying with minimum laws regulating the workplace, and fairness interests above and beyond those minimums. Employees might then regard the employer as more likely to comply with the letter of the law-for instance, avoiding overt discrimination based on gender or race. In this case, perceived legal compliance should increase, while procedural justice should decrease following DRS implementation. This view is plausible in light of findings by Feldman and Tyler (2012) on perceived procedural justice when employers are legally mandated to implement fair procedures. The authors hypothesized that employees distinguish between "mandates that provide a basic level of security in the workplace and additional procedural mechanisms that they view as more discretionary." 
Research on mandatory arbitration of employment disputes lends further support for the notion that employees' perceived legal compliance could increase when procedural justice decreases (with DRS implementation). Researchers generally found positive justice perceptions associated with voluntary dispute resolution processes or those in unionized settings that were the result of collective bargaining. Whether mandatory arbitration can similarly enhance perceptions of justice in a nonunion setting when an employer unilaterally implements the DRS is an important but under-analyzed question (Batt, Colvin, and Keefe 2002). Some suggested it creates opportunities for due process (Zack 1999), but others were more skeptical of such claims (Stone 1996; Schwartz 2009). Recent research suggested another reason why procedural justice perceptions might decrease while perceived legal compliance increases with DRS implementation in a nonunion setting. A qualitative study of employees who signed mandatory arbitration agreements as a condition of their employment suggested that employees may regard these agreements as attempts by the company to insulate itself from legal liability (Eigen 2008). This belief may be due in part to the formal, legalistic, and contractual way in which such agreements are typically presented. Employees might assume that if corporate headquarters insists they sign something that looks like a legal document, the company is doing so to protect its legal interests. It is therefore possible that employees could interpret a mandatory arbitration component of an employment DRS as a legal means of insulating corporate rights in a way that fosters overall distrust in the corporate entity because it appears to take away important employee legal rights, such as the right to a jury trial, even while simultaneously augmenting the degree of perceived legal compliance by the company on concerns such as sexual harassment and discrimination. This theory is consistent with Feldman and Tyler's (2012) work described above. In Figure 2, we present the differential effects model depicting the described interrelationship among DRS implementation, organizational justice, and perceived legal compliance.

In spite of repeated calls for empirical research in this area, as other researchers have observed, little is known about how implementation of DRSs affects organizational justice and organizational commitment for that vast share of employees who never bring complaints through the system (Budd and Colvin 2008; Mahony and Klaas 2008). Much has been said about employee/claimants and their experiences with dispute resolution. Much has been written about the difference between claimants and non-claimants. But little is known about the impact (if any) of implementation of a workplace DRS on current employees who know about the DRS's implementation but will likely never participate in a claim brought through the DRS. Casting this wider net of employees is useful because research has mostly focused on claimants and participants, or has compared those smaller groups of employees to non-claimants post-implementation of a DRS. We believe this is the first attempt to offer an empirical assessment of the impact of implementing a workplace dispute resolution system in a nonunion 
Figure 2. Differential Effects Model Connecting DRS Implementation, Organizational Justice, Legal Compliance, and Organizational Commitment

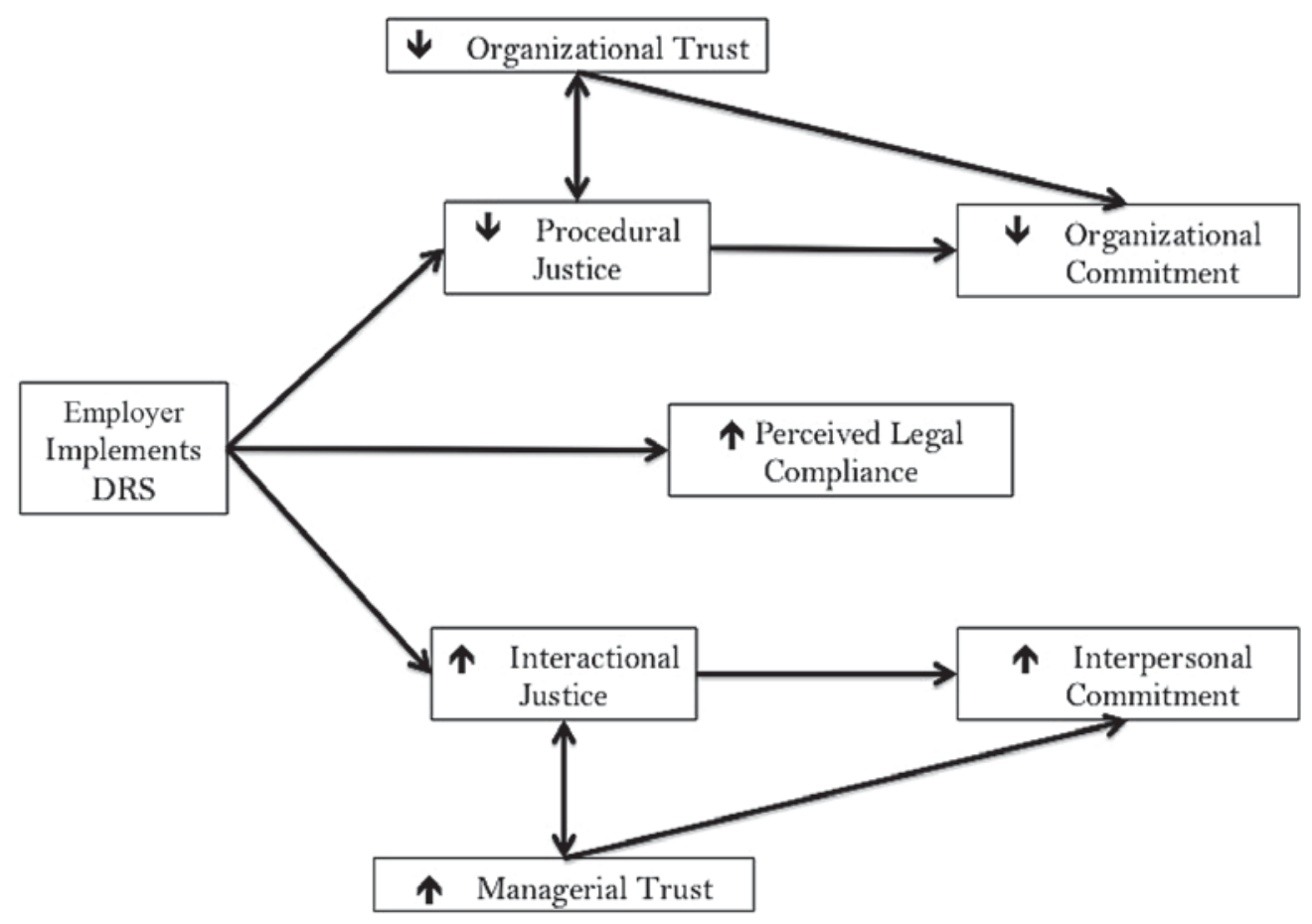

setting on this wider-cast net of all currently employed workers using preand post-DRS implementation data on organizational justice, organizational commitment, and perceived legal compliance of a group of employees in the private sector large enough to render meaningful statistical analysis possible.

We focus on employees' perceptions of justice and other survey data reporting their opinions-but not behavior such as turnover-for three reasons. First, for employees who have not initiated disputes themselves, one would not expect a significant effect of implementation of a DRS on exiting behavior. The relatively low-skilled nature of the work of frontline employees' at Gilda's disadvantages these employees in the outside labor market, suggesting that, in this context, exit rates would be a flawed measure of the impact of the DRS (Edwards and Scullion 1982). Second, behavioral measures like firm exit are more likely explained by factors other than DRS implementation, such as how badly employees need the job or whether their expectations for the job are short- or long-term. Third, employees cannot exit the firm anonymously, but they can (and do, in the data we analyzed) report their honest views about the critical constructs like organizational justice, organizational commitment, and perceived legal compliance. Because these constructs are critically linked to other important measures described above, the survey data we use are uniquely suited to the present analysis. In some respects, they offer more salient information than behavior. Observing an employee exiting the firm tells us nothing about the 
employee's motivations for leaving, without which we have no information about the relationship between the DRS and any implementable HR interventions.

\section{The Employer's DRS}

We analyze eight years of data from a single company that operates in the United States, "Gilda's, Inc." It employs more than 100,000 workers in more than 1,000 locations. The company implemented a four-step DRS for all of its employees in all of its locations that went into effect on January 1, 2004. Our understanding from reviewing records and talking with individuals in Gilda's corporate Human Resources (HR) department is that the rollout of this DRS did not occur at the same time as anything else that might be expected to shock employees' perceptions of their managers or the company, nor was the introduction of the DRS part of a larger, company-wide initiative to revamp other aspects of work. Prior to the introduction of the DRS, employees were encouraged to report claims of illegal treatment in violation of federal and state law to their managers or to Gilda's corporate HR department, which maintained a toll-free, call-in number for employees who wished to make claims anonymously.

Like many workplace DRSs, the program at Gilda's starts informally with claim initiation with local supervisors, escalates to formal review by corporate-level HR, and culminates in final, binding, mandatory arbitration. More specifically, the four steps of Gilda's DRS are as follows:

1) An employee may initiate a claim and attempt to resolve it with his local manager;

2) If unresolved to his satisfaction at the local level, an employee may then report his claim to corporate $\mathrm{HR}$, and someone will attempt to resolve the claim;

3) If unresolved to his satisfaction by HR, a claimant may then escalate his claim and choose between a determination made by a peer-review panel consisting of three fellow employees, or, by a unilateral determination made by another HR department member; and

4) If still unresolved to the employee's satisfaction, he or she may initiate a claim to be brought before final, binding arbitration.

All newly hired employees complete typical employment forms and sign a contract binding them to resolve any and all legal claims in arbitration. The orientation process is run by local managers based on talking points provided to them by Gilda's corporate HR department. New employees watch a

\footnotetext{
2"Gilda's" is the pseudonym chosen to protect the company's anonymity. The authors are bound by a confidentiality agreement with Gilda's that restricts our ability to offer more background information about the organizational and workplace context surrounding the DRS implementation.
} 
short video that plainly describes the four-step DRS. Local managers are responsible for explaining the DRS to their employees.

Gilda's four-step DRS is typical of private sector employment DRSs in two key ways. First, it covers employee claims ranging from generic unfair treatment or complaints about random nonlegal matters to highly legalized claims such as discrimination or harassment under Title VII of the Civil Rights Act of 1964. Second, Gilda's DRS contains two distinct components: an informal, localized piece (step 1), followed by a formal, adjudicatory one (steps 2-4).

\section{Data and Methods}

\section{Survey Instrument and Variable Construction}

At its peak over the 2000-2007 sample period, Gilda's employed more than 100,000 workers in more than 1,000 locations. Each April, about one-third of these locations were chosen at random to participate in an annual, paperand-pencil survey on employment relations and HR matters. Occasionally, a few stores might be added to the annual sample if senior management had a particular interest in a given store. The most likely reason this would occur is because the otherwise random selection of stores had perennially omitted a location. Since the survey was administered during regular working hours, it achieved an impressive $80 \%$ response rate even in the absence of any financial incentive for completion other than paid time away from one's usual employment responsibilities.

While the sheer quantity of data shared by Gilda's is massive-more than 300,000 worker survey responses spread across eight survey years- the data were not originally collected for research purposes. This engenders two types of challenges-creating a cleanly and confidently linked panel data set of store-years and constructing appropriate employment relations and HR indices. First, it was not always perfectly obvious when observations from a given store could be reliably linked to that store's observations in other years. Though Gilda's uses a numbering system for its stores, there were times when identical store numbers were associated with slightly different store descriptions or when identical store descriptions appeared to be associated with multiple store numbers. We resolved as many of these anomalies as possible with help from Gilda's management and from reliable external sources. When we were not able to confidently reconcile survey responses, we dropped them from the analysis. Furthermore, while the original sampling frame included mid-level managers, part-time employees, and workers in supporting roles, we excluded them to ensure that all workers surveyed were frontline workers, doing essentially the same work. In the net, this yielded 215,140 frontline worker responses from 635 different stores over the eight-year period.

The second challenge this company-collected data makes for research is the roster of actual survey items and the indices that we worked to create 
from them. The items themselves were neither developed from pre-validated scales nor kept completely identical across survey instruments. While it is safe to assume that all employees surveyed in a given year in a given store responded to the same instrument, the survey instruments did vary slightly from year to year and even between regions in a given year. In general, each instrument included between 20 and 40 items, all of which were answered on a 5-point Likert-type scale in which $1=$ "strongly disagree" and $5=$ "strongly agree." We addressed this inconsistency issue first by identifying each of the distinct survey questions asked over all of the survey instruments, allowing even small changes in wording to constitute a distinction. This exercise yielded about 90 "unique" survey items. The researchers then worked independently to group the items by "theme," for example, questions regarding perceptions of procedural justice, or questions regarding the quality and frequency of managerial communication. This yielded surprisingly similar and thus (inter-rater) reliable groupings (Schwab 2005).

Ideally, we could then verify high inter-item reliability by computing something along the lines of a Cronbach's $\alpha$, where a large $\alpha$ could justify our coalescing the items into a named index. None of the groupings, however, yielded any observations that contained values for every single one of its constituent items, thereby preventing our use of the standard estimate of reliability, or of similar data reduction techniques such as factor analysis. ${ }^{4}$ Consequently, we created scales by taking "row means"-averaging scores across the items constituting a given index or scale, for however many nonmissing items are available, for a given observation. ${ }^{5}$ The end result is a set of four employment relations measures that emerge directly from the data, the very same data that the company itself relied on to make and assess its HR strategy. Moreover, the four emergent variables span a range of measures that combine to paint a rich picture of the broad employment relations and HR climate pre- and post-DRS.

The definitions of these variables as well as the construction of each index are detailed in Table 1. Procedural justice relies on eight items to assess employees' perceptions that they 1) have access to formal mechanisms for appealing adverse employment actions, and 2) are afforded the opportunity to speak up in their dealings with the company and its agents. This assessment comports with the way others have defined and measured procedural justice (Naumann and Bennett 2000; Colquitt, Noe, and Jackson 2002; Aquino, Tripp, and Bies 2006). It is also harmonious with the more informal manifestations of voice that are of increasing interest to organizational

\footnotetext{
${ }^{3}$ The surveys also posed two or three open-ended text questions, but we were not provided the employees' responses to these questions.

${ }^{4}$ Factor analysis, for example, relies on list-wise deletion, which in this case, yields an empty data set.

${ }^{5}$ That is, the summative score is divided by the number of items for which the sum was calculated. For example, if only five of eight items had non-missing values, then the five items would be summed and divided by five. This approach is consistent with the way index values are imputed from the usual construction of a summative index using Cronbach's $\alpha$ if one or more items underlying the index are missing for a particular observation.
} 
Table 1. Variable Definitions and Construction

Variable Definition in italics, with actual survey questions underneath

Dispute Resolution System (DRS)

Is the DRS in place? (binary variable in which $0=$ "no" and $1=$ "yes")

Procedural Justice

Interactional Justice

Legal Compliance

Organizational Commitment

Employees have access to formal mechanisms for appealing adverse employment actions and are afforded voice in their dealings with the company and its agents.

If I have a problem, there is someone in senior management I can go to who will assist me.

This location has an effective means of appealing discipline and discharge actions.

If I can't get a problem resolved in my store, HR continues to be accessible to me and provides guidance.

I believe that this company is committed to resolving associate concerns or problems quickly and in a fair manner.

My direct supervisor is interested in my opinion on work-related issues.

My general manager listens to employees' concerns, issues, and suggestions.

My manager is interested in my opinion on work-related issues.

If I have a problem, there is a manager in my location I can go to for help.

Local store managers and supervisors treat employees with respect and sensitivity.

My manager regularly shows me that he/she cares about me.

My direct supervisor treats me with courtesy and respect.

My direct supervisor regularly shows me that he/she cares about me.

Once my schedule is posted, my manager only makes changes that I agree to.

The workplace is in compliance with the law, particularly laws against harassment and discrimination.

I feel my work environment is free from harassment and discrimination.

My supervisor manages everyone in my group equally regardless of their race, age, or sex.

My direct supervisor manages everyone in my group equally regardless of their race, age, or sex.

I think the company is doing a great job of providing a workplace free from intimidation, threats, and other behaviors that could impact my safety.

Racial, ethnic, and gender-based comments/jokes are not tolerated at this location.

I feel I am treated fairly and with respect regardless of my race, gender, or age.

I feel my work environment is free from discrimination based upon gender, race, age, or sex(ual orientation).

Employees feel committed to the organization.

Work like mine greatly encourages me to do my best.

The supervision I receive is the kind that greatly encourages me to give extra effort.

I expect to be working here one year from now.

My job is considered important in this company.

I believe in what we are doing in this store.

I feel positive about the opportunity here to advance my career.

Note: With the exception of the DRS dummy, all variables are continuous and measured on a Likert-type scale such that $1=$ "strongly disagree" and $5=$ "strongly agree." 
justice researchers (Detert and Trevino 2010; Klaas, Olson-Buchanan, and Ward 2012) and that interviews revealed were at play in the workplaces under study. So, procedural justice measures employee comfort initiating claims as well as the perception that the entity (e.g., Gilda's as a whole, the HR department), the person (e.g., a local supervisor or manager), or the process addressing the claim, be it informal (i.e., step 1) or formal (i.e., steps 2-4) (Tyler and Blader 2000), does so in a neutral, effective, and fair manner. Therefore, the survey questions also align with descriptions of access and problem-solving viability described in several studies outlining critical elements by which to gauge the effectiveness with which disputes are addressed in a workplace with or without a DRS in place (Folger and Bies 1989; Tyler and Bies 1990; Sheppard, Lewicki, and Minton 1992).

Recall that interactional justice is distinct from procedural justice in that the former explicitly excludes voice, even one's expression of her opinion to her immediate supervisor. Rather, interactional justice captures the extent to which store managers and supervisors treat employees with respect and sensitivity. So, the construct reflects the degree to which workers feel well-treated, not by "the company" per se, but by managers and direct supervisors with whom they deal on a personal level. In other words, in the course of everyday managerial decision-making, are one's needs being taken into account (Bies and Moag 1986; Aquino, Lewis, and Bradfield 1999; Bies 2001)? We construct the measure of interactional justice from four survey items that align closely with validated scales used by Moorman (1991) and Niehoff and Moorman (1993).

Legal compliance tracks employees' perceptions not of how they are treated, but rather the degree to which the firm is regarded as following the law, particularly with respect to laws prohibiting discrimination and harassment. Such compliance is an often overlooked but critical component of workplace governance (Balser 2000; Wallace et al. 2008). This tracking allows for a nuanced examination of DRS effectiveness, whereby workers may believe the law is being better followed post-DRS, whether their personal treatment has improved or not. Finally, to vet the traditional model linking DRS implementation with loyalty to the firm, we measure organizational commitment as well. The literature frequently relies on turnover as a measure of organizational commitment (Spencer 1986; Byrne 2005). As explained above with respect to other behavioral measures, however, both practicality and the study context dictated that we rely on perceptual measures of organizational commitment. Indeed, the six survey questions making up this construct align well with commonly used validated scales (Mowday, Steers, and Porter 1979; Cook and Wall 1980).

While the indices were constructed using worker-level data, the multivariate analysis relies on a store-level data set, created by taking means of each of the resulting indices by store-year. Since stores can be linked from year-toyear but individuals cannot, the decision to use store-years as the unit-ofanalysis allows us to take advantage of powerful techniques for analyzing cross-sectional times series (panel) data. Given the conservative pruning of 
the data described above, the resulting data set includes 1,171 store-years representing 635 distinct stores. Table 2 shows the number of stores contributing observations for each of the dependent variables, by year. The employment relations and HR measures serve as dependent variables in the sense that their movement over time should reflect the impact of Gilda's DRS. The latter is the focal independent variable and is operationalized as a binary variable equal to one for years 2004 onward.

In the aggregate, while cognizant of the challenges as well as the opportunities presented to us by these data, we believe that the judgments made in assembling the panel as well as those made in constructing the employment relations and HR measures work to attenuate rather than to bias our estimates, engendering a collectively conservative assessment of the impact of Gilda's DRS.

\section{Empirical Strategy}

Gilda's DRS went into effect for all employees at all locations right in the middle of the observation period-January 1, 2004. Therefore, the data allow us to track movements in employment relations variables over time, including the impact of a policy-induced discontinuity beginning with the 2004 observations. While we cannot rule out alternative explanations for the effects of implementing the DRS caused by contemporaneous exogenous shocks, we have no reason to suspect that this is occurring. As noted above, our use of store-level data to analyze the effects of implementing the DRS avails us of fixed-effects (FE) models to account for time-constant unobservables at the store level. We detail these methods below.

As a first pass, we will simply compare the mean values for our four dependent variables before and after the implementation of the DRS. To claim that any discontinuity is associated with the implementation of Gilda's DRS, however, we would need to control for store-level variables that could explain the otherwise relatively "smooth" variation over time in employment relations outcomes. While we have little information on each store other than its yearly "bag" of survey responses, we can generally match each store's responses in a given year to its responses in all other years. Consequently, we can control for all store-level, time-constant, unobservable sources of variation in employment relations measures. We can do this first by simply augmenting the differences-in-means tests to account for store-level fixed effects. These tests, while easy to interpret, still allow for the possibility that time-varying unobservable variables are biasing the estimated impact of the DRS on the dependent variables. Therefore, we will also offer a more sophisticated model that at least partially accounts for these time-varying unobservable drivers of employment relations outcomes.

The most transparent and conservative way to do this is to consider samestore values of each dependent variable pre- and post-DRS, net of as many confounding effects as possible. The longitudinal nature of the data facilitates this effort first by allowing us to estimate FE models to account for 


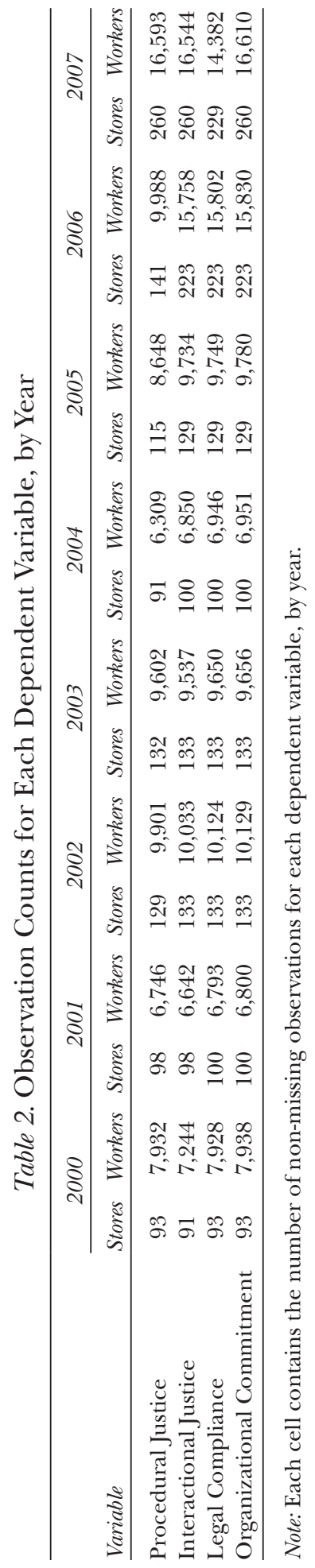


time-constant unobservable drivers of employment relations at the storelevel (Baltagi 2005). From a practical perspective, this requires a model that includes a vector of 635 store-specific dummies on the right-hand side. Second, reliance on panel data also facilitates a way of dealing with time-varying unobserved variables that could be positively correlated with both the implementation of the DRS and of the dependent variables, factors that could bias the critical estimates of the slope coefficient associated with the DRS. It is important to note that since the DRS was instituted centrally and simultaneously across all stores and by Gilda's senior management at corporate headquarters, many of these unobserved variables would likely be companyor even economy-wide, not store-specific. Therefore, we can strip the estimates of some of these time-varying unobservables by including an additional vector of binary variables-one for each year-on the right side of the equation. Formally, we model employment relations and HR variables using a multilevel model,

$$
y_{i t}=\sum_{k=1}^{635} d_{k} \alpha_{k}+\sum_{T=2001}^{2007} d_{T} \alpha_{T}+\beta_{i t} x_{i t}+\varepsilon_{i t},
$$

where $y$ represents any one of the four employment relations variables for store $i$ in year $t$ and $\varepsilon_{i t}$ is a zero-expectation error term. The first term on the right side represents a dummy variable for each store, $d_{k}$, multiplied by a store-specific intercept, $\alpha_{k}$. Since there is no shared intercept term (akin to $\alpha_{0}$ ), this entire first term can be simplified to $\alpha_{i}$, a single intercept term for store $i$. Similarly, the second term adds a dummy, $d_{T}$, for each year other than the first year, 2000, multiplied by a year-specific intercept, $\alpha_{T}$. This captures the year-specific mean of the dependent variable, and can thus be simplified to $\alpha_{t}$. Consequently, Equation 1 can instead be written as

$$
y_{i t}=\alpha_{i}+\alpha_{t}+\beta_{i t} x_{i t}+\varepsilon_{i t}
$$

where the key explanatory variable-the binary representing the implementation and ongoing use of the DRS-is represented by $x_{i t}$. Therefore, the focal coefficient estimate is $\hat{\beta}_{i}$, which measures the impact of the DRS on the dependent variable, net of unobserved sources of store-specific and year-specific variation. To further err in a conservative direction, we compute standard errors using the generalized Huber-White formula clustered by store, allowing for arbitrary correlations of residuals among store-year observations (Bertrand, Duflo, and Mullainathan 2004). ${ }^{6}$

\section{Results}

Table 3 shows descriptive statistics and correlations for the focal independent variable as well as for the four employment relations measures. Note

\footnotetext{
${ }^{6}$ In almost all cases and as expected, the standard errors calculated by the Huber-White formula are only minutely greater than the standard errors that otherwise emerge from this model, because the model already accounts for the dependence structure of the data.
} 
Table 3. Means, Standard Deviations, and Correlations for Study Sample

\begin{tabular}{|c|c|c|c|c|c|c|c|c|}
\hline \# & Variable & Mean & $S D$ & 1 & 2 & 3 & 4 & 5 \\
\hline 1 & Dispute Resolution System & .56 & .50 & 1.00 & & & & \\
\hline 2 & Procedural Justice & 3.49 & .34 & -.23 & 1.00 & & & \\
\hline 3 & Interactional Justice & 3.88 & .32 & .37 & .27 & 1.00 & & \\
\hline 4 & Legal Compliance & 3.80 & .32 & .24 & .51 & .60 & 1.00 & \\
\hline 5 & Organizational Commitment & 3.63 & .25 & -.14 & .73 & .49 & .43 & 1.00 \\
\hline
\end{tabular}

Note: Sample sizes differ by cell, but range from $n=1,028$ to $n=1,171$ store-years.

Key: All correlation coefficients are significant at $p<.0001$.

that about $56 \%$ of the observations are post-DRS. Interestingly, both procedural justice and organizational commitment reveal a negative, zero-order association with the DRS, while interactional justice and legal compliance are positively, pair-wise correlated with the DRS. Delving more deeply into the employment relations variables, recall that each is measured on a 5point, Likert-type scale in which 1 = "strongly disagree" and $5=$ "strongly agree." Therefore, since the means for these variables are all in the range from 3.49 to 3.88, all are somewhere between the neutral response ("neither agree nor disagree") and agreement.

The most straightforward demonstration of a difference in the values of the dependent variables between the pre-DRS and post-DRS periods would be with a simple difference-in-means accompanied by a $t$-test of that difference. Unfortunately, this test is precluded by the fact that the same stores appear repeatedly, from one to six times over the 2000-2007 observation period, violating the independence assumption that underpins a standard $t$-test. We therefore calculate the pre- and post-DRS means and the differences between them by backing them out from a random effects regression model that accounts for the dependence between stores. The results can be interpreted as one would normally interpret a difference-in-means. The $t$ statistic, however, is replaced by a $z$-statistic owing to the fact that the null hypothesis for a variance components model assumes a normal sampling distribution rather than a $t$-distribution. ${ }^{7}$

Table 4 presents these simple differences-in-differences for each of the dependent variables. First focusing on procedural justice, note that its mean value across all stores in the pre-DRS period was 3.59 on a scale ranging from 1 to 5 , where 1 is low and 5 is high. In the post-DRS period, the mean score for procedural justice is 3.37. This represents a 0.21 decrease in this dependent variable. It accounts for the nonindependence of observations by stores, making the test-of-significance more conservative. Even so, the 0.21 reduction in procedural justice is highly statistically significant $(p<$ .001). The results for the other three dependent variables can be interpreted similarly. On the one hand, post-DRS observations reveal measurably

\footnotetext{
${ }^{7}$ Because the finite sample distribution for a variance components model does not have a simple form, most researchers and most statistics packages rely on the asymptotic (i.e., large-sample) sampling distribution (Skrondal and Rabe-Hesketh 2004).
} 
Table 4. Mean Values for Dependent Variables

before and after the Implementation of a Dispute Resolution System, Not Accounting for Unobserved Differences across Stores

\begin{tabular}{lcccc}
\hline Dependent Variable & Pre-DRS & Post-DRS & Difference & z-statistic \\
\hline Procedural Justice & 3.59 & 3.37 & -.21 & $-12.22^{* * *}$ \\
Interactional Justice & 3.67 & 3.98 & .31 & $19.37^{* * *}$ \\
Legislative Compliance & 3.64 & 3.84 & .20 & $12.60^{* * *}$ \\
Organizational Commitment & 3.65 & 3.59 & -.06 & $-4.81^{* * *}$ \\
\hline
\end{tabular}

Notes: Table reports pre-DRS and post-DRS means calculated as the linear combination of the constant and the coefficient on a DRS dummy for random-effects regression estimates of each of the dependent variables. Statistical significance accounts for the clustering of observations by store.

Key: $* p<.05, * * p<.01, * * * p<.001$

greater values than their pre-DRS counterparts, all at very high levels of statistical significance, for interactional justice and legislative compliance. On the other hand, mean scores for organizational commitment fall very slightly, by 0.06 , also statistically significant at the $p<.001$ level.

The results reported in Table 4 can be made slightly more robust by treating the separate stores in the data not as a "nuisance" factor to be accounted for but as an explicit source of variation in the dependent variables. Along these lines, Table 5 presents differences-in-means that parallel the results in Table 4. In this case, the means are backed out of a fixed-effects estimate that includes a vector of binary variables, one for each of the separate stores in the data. These dummy variables "soak up" any part of the variation in the dependent variable that can be accounted for by time-constant, unobserved attributes of each individual store.

The results in Table 5 may be interpreted almost identically to those in Table 4, the only difference being that these results can be thought of as "within-store" effects. Looking at procedural justice once again as an illustration, on average, within a given store, perceptions of procedural justice fell by 0.22 between the pre-DRS and post-DRS periods. This difference is about the same as the difference-in-means when unobserved differences

Table 5. Mean Values for Dependent Variables

before and after the Implementation of a Dispute Resolution System, Accounting for Unobserved Differences across Stores

\begin{tabular}{lcccc}
\hline Dependent Variable & Pre-DRS & Post-DRS & Difference & t-statistic \\
\hline Procedural Justice & 3.59 & 3.37 & -.22 & $-10.69^{* * *}$ \\
Interactional Justice & 3.66 & 3.98 & .32 & $17.15^{* * *}$ \\
Legislative Compliance & 3.66 & 3.83 & .17 & $10.79^{* * *}$ \\
Organizational Commitment & 3.63 & 3.61 & -.03 & $-2.20^{*}$ \\
\hline
\end{tabular}

Notes: Table reports pre-DRS and post-DRS means calculated as the linear combination of the constant and the coefficient on a DRS dummy for fixed-effects regression estimates of each of the dependent variables. Statistical significance accounts for the clustering of observations by store.

Key: $* p<.05, * * p<.01, * * * p<.001$. 
between stores are not accounted for $(0.21)$. In this case, the differences are tested with the usual $t$-statistic, since the fixed-effects model yields a finite sample distribution with a shape than can be easily determined based on the degrees of freedom. Overall, the results are qualitatively identical to those in Table 4, implying that pre-post differences in the mean values of the dependent variables cannot be attributed to unobserved factors at the store level. The one partial exception, however, is organizational commitment. While the before-and-after difference remains statistically significant, it loses precision in Table 5 relative to Table 4, suggesting that some unobserved characteristic at the store-level is at least partially responsible for the apparent correlation between organizational commitment and the DRS. Nonetheless, relative to the pre-DRS period, within the same stores, perceptions of procedural justice and measures of organizational commitment decreased while perceptions of interactional justice and legislative compliance both increased.

What the results in Tables 4 and 5 do not account for are time-varying firm- and economy-wide unobservables that could also be correlated with both the DRS dummy and the dependent variables. The omission of these variables could allow for effects to be wrongly attributed to the DRS. Therefore, the regression estimates in Table 6 allow for a more nuanced analysis of the employment relations variables, one that teases out the impact of the DRS not only from the other store-level drivers of the dependent variables, as in Table 5, but also from year-specific forces that impinge on the dependent variables. Each model estimates Equation 2 independently for each of the enumerated employment relations variables. Stepping through Model 1 to illustrate, notice that even after controlling for store-fixed and year-fixed effects, the introduction of the DRS is associated with a 0.30-point decrease in the 5-point measure of procedural justice. Not only is this slightly larger than the effect estimated in the absence of year dummies, the estimate

Table 6. Fixed-Effects Estimates of the Impact of a Dispute Resolution System on Employment Relations Outcomes

\begin{tabular}{lcccc}
\hline Model 1: & $\begin{array}{c}\text { Model 2: } \\
\text { Indepedural } \\
\text { Justice }\end{array}$ & $\begin{array}{c}\text { Model 3: } \\
\text { Justice }\end{array}$ & $\begin{array}{c}\text { Model 4: } \\
\text { Compliance }\end{array}$ & $\begin{array}{c}\text { Organizational } \\
\text { Commitment }\end{array}$ \\
\hline Dispute Resolution System & $-.30^{* * *}(-6.13)$ & $.33^{* * *}(9.11)$ & $.36^{* * *}(9.60)$ & $.001(0.03)$ \\
$n_{\text {store years }}$ & 942 & 1,049 & 1,032 & 1,053 \\
$n_{\text {distinct stores }}$ & 492 & 527 & 527 & 528 \\
$\rho$ & .59 & .54 & .63 & .54 \\
$R^{2}$ & .37 & .51 & .25 & .03 \\
\hline
\end{tabular}

Notes: Table reports coefficient estimates and associated $t$-statistics from longitudinal regression models on panel data, with standard errors clustered by store location. All models include dummy variables for each survey year and for each store. Therefore, models estimate fixed-year and fixedstore effects, where $\rho$ is a measure of intraclass correlation. The $R^{2}$ reported is the "within-" $R^{2}$, meaning that it does not reflect the explanatory power arising from the large vector of store dummies or from "between-store" differences in the independent variables.

Key: $* p<.05, * * p<.01, * * * p<.001$. 
achieves the same level of statistical significance $(p<.001)$. The model explains $37 \%$ of the within-store variance in procedural justice across the 492 stores that were able to provide data for this index, and thus, that were included in the estimate. Each store lent, on average, 1.9 observations (942 492) to the estimate of Model 1. Finally, $\rho$ is the share of the estimated variance of the overall error, $\varepsilon_{i t}$, accounted for by effects at the store level, a measure of intraclass correlation. In this case, $59 \%$ of the variability in procedural justice can be attributed to differences between (versus within) stores. This value for $\rho$ bolsters our analysis in two ways. First, it substantiates our decision not to estimate conventional OLS models, since OLS requires that $\rho=0$ (Singer and Willett 2003). Second, it justifies our decision to model the dependent variable at the store-level as opposed to the personlevel as individual survey responses in a given year do, indeed, cluster within a given store. The remaining three models can be interpreted similarly. The implementation of the DRS is associated with increased perceptions of interactional justice and of legal compliance. Interestingly, in the case of legislative compliance, the estimated effect of the DRS, accounting for firm- and economy-wide unobservables by year, are actually larger than they were for estimates that do not include year dummies (shown in Table 5). Finally, Model 4 attempts to predict organizational commitment using the exact same model and right-hand-side variables as the other three models. Note that the same variables that shed light on justice and legal compliance do very little to illuminate the drivers of organizational commitment. Moreover, by comparing the Model 4 estimates to the differences-in-means in Tables 4 and 5, we can see that no simple relationship is observed between the DRS and organizational commitment as occurs between the DRS and the other three dependent variables.

Nonetheless, in the net, the regression results support the theory that the DRS affected the workforce in a bifurcated manner, decaying at perceptions of procedural justice while boosting perceived levels of interactional justice. The DRS, on average, was also associated with increased perceptions on the part of frontline employees that Gilda's was, indeed, complying with the law. Once store-level and year-level effects are controlled for though, no evidence supports a simple, DRS-induced change in organizational commitment.

\section{Discussion}

By offering evidence of the effects of implementing a typical workplace DRS with both formal and informal components, we present a case that calls into question the extant model connecting DRS implementation, procedural justice, and organizational commitment. Implementation of Gilda's DRS is associated with improved perceived interactional justice, improved perceived legal compliance, and reduced perceived procedural justice, but has no identifiable effect on organizational commitment. Limitations of this natural experiment notwithstanding, the evidence in this article suggests 
Figure 3. Observed Means of Dependent Variables by Year (Individual Level Data)

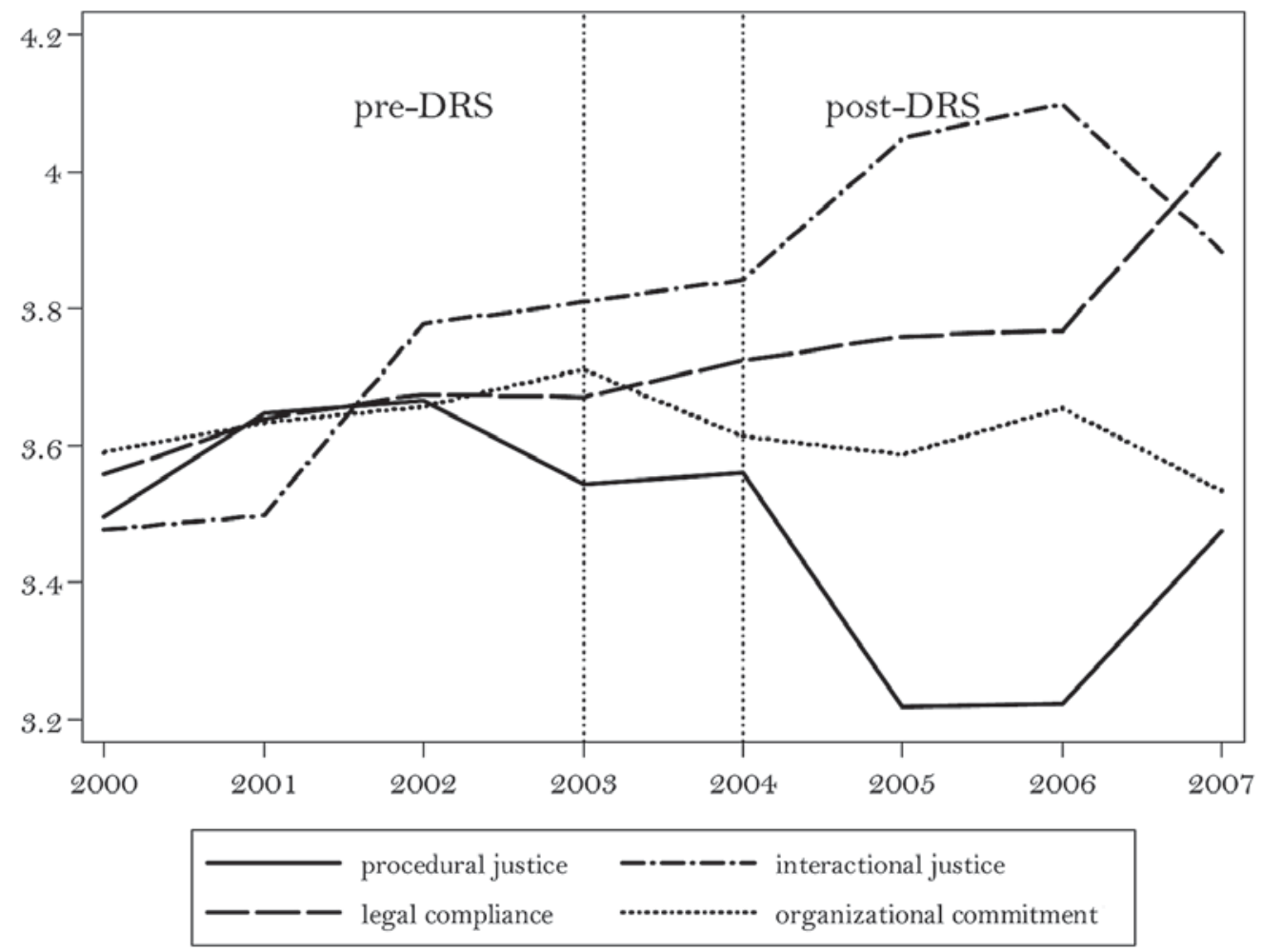

that implementation of Gilda's DRS improved frontline employees' perceptions of interactional justice. Perhaps the trade-off for this benefit of implementing a DRS such as Gilda's is a decrease in procedural justice found in this study. These findings lend support for parts of the model depicted in Figure 3 .

Our findings might reflect the way in which local managers explain Gilda's DRS to employees, and the fact that local supervisors are perceived by Gilda's corporate HR department as being better at their jobs if fewer employee claims are escalated, consistent with received case study research of nonunion systems implemented elsewhere (Colvin 2004). They are encouraged and rewarded for resolving claims at the local level. Immediate supervisors might be incentivized to encourage their employees to trust them to resolve claims instead of allowing HR or Gilda's as a corporate entity to do so. Perhaps local managers actively encourage employees to trust them, which could be interpreted implicitly as being encouraged to distrust Gilda's DRS or the company writ large.

Implementation of the DRS is most strongly associated with an increase in employees' perceptions that the company is in compliance with the law. This observation might seem counterintuitive at first given the lack of effect on organizational commitment and the decrease in perceived formal procedural justice, which could be interpreted as a lack of trust in Gilda's to fairly 
resolve disputes internally. The observed concurrent increase in Gilda's employees' perceived legal compliance and decrease in perceived procedural justice is consistent with recent research (Eigen 2008; Feldman and Tyler 2012). One possible explanation for why employees regard the company as more compliant with the law and simultaneously less fair in resolving disputes is that being made to sign a form-contract requiring acquiescence to final, binding, mandatory arbitration makes the company's intent to be "legally compliant" more salient to them. This way of thinking is likely to be the case here since the form explicitly mentions coverage of employment discrimination and harassment and other statutory claims. Employees may regard the formal processes associated with the DRS and Gilda's requirement that they contract away their right to a jury trial as a signal that the company takes its legal rights and obligations more seriously on a goingforward basis. This explanation derives from employees' perceptions of the formal aspect of the DRS and is consistent with the approach suggested by Tyler and Blader (2000). Future research should continue to explore how bifurcated systems consisting of both formal processes invoking legal rights adjudication, such as mandatory arbitration, and informal procedures, such as reporting complaints to local managers, invoke differentiated organizational justice findings such as those described in this study.

Alternatively, employees might believe the company complies with the law because of the heightened trust and comfort with local management. Employees might feel that they are treated fairly by local supervisors and that their concerns are genuinely heard by local management. In turn, employees may be more likely to perceive local management as being compliant with laws that prohibit discrimination based on gender, race, or age. This explanation accords with research that suggests that employees overbroadly characterize "unfair" behavior as "illegal" (Bies and Tyler 1993). It also implies the converse: that they over-broadly characterize "fair" behavior as "legal." It is hard to tell if the augmented legal compliance perceptions are related to the positive effects of interactional justice or the negative effects of procedural justice. Further research should explore which accounts for the observed effects.

The Gilda's case offers rare insight into employees' perceptions of important workplace metrics before and after the implementation of a workplace DRS. The findings suggest that more attention should be paid to the bifurcated components of dispute resolution systems. Specifically, it may make sense for researchers to more carefully discern informal from formal processes because the latter are more closely associated with the corporate entity and the former with individual local managers responsible for administering DRSs and handling disputes at their earliest stages. Our findings also lend indirect support for complementarity models of dispute resolution like that offered by Bendersky (2003), which suggest that varying the degree of input into the process and the flavor of the dispute resolution system at-hand differentially impacts the non-disputant population. Finally, this study indicates the need to focus research efforts on understanding 
differential effects of organizational change on perceptions of local versus nonlocal management, particularly as related to the standard exit-voiceloyalty model. As other studies have shown, employees may differ in the degree to which they feel committed to organizations locally versus globally (Gregersen and Black 1992) and organizationally versus personally (with respect to their immediate supervisors) (Becker, Billings, Eveleth, and Gilbert 1996). As illustrated by the full version of the differential-effects model shown in Figure 3, it could be that a trade-off occurs between formal and informal procedural justice similar to the observed trade-off between interactional and procedural justice that results in less organizational commitment but greater interpersonal commitment (to immediate supervisors and managers), concurrently with increased perceived legal compliance by the organization.

\section{Limitations}

This study has a number of limitations. Like most case studies that exploit data from a single organization, one can reasonably question the generalizability of the findings. As noted earlier, however, the four-step process instituted at Gilda's-where disputes are first dealt with informally, and then with increasing formality, until the final step, binding arbitration-very closely resembles the archetypal DRS found in nonunion firms (Colvin 2011; Eigen, Menillo, and Sherwyn 2012). Indeed, this is part of what made Gilda's such an attractive site for undertaking the first analysis of this type, in which a wide range of workforce and work-related variables could be held in place. To the extent that legitimate challenges to the generalizability of our findings persist, we believe that the internal validity allowed for by the organizationally bounded nature of our data is a worthwhile dividend, particularly given the dearth of pre- and post-analyses of the impact of a DRS.

Closely related to the issue of generalizability-or external validity-is the notion of construct validity. As mentioned above, the data relied on in this study were not originally collected for research purposes, and therefore, do not reflect the level of care and meticulousness that researchers take when crafting survey instruments and constructing variables for analysis. Most important, Gilda's and its survey vendor made limited appeal to pre-validated scales. They also allowed for slight changes year-to-year and between regions in both the precise phrasing of and the composition of survey items, challenges that we addressed as conservatively and transparently as possible. Notwithstanding these issues, we defend the use of these data in two ways. First, the questions asked on the annual survey likely reflected issues with which Gilda's management were most concerned. The information provided in the survey responses - the exact same data that we rely on in our analysis-underpinned the firm's justification for creating a structured approach to dispute resolution in the first place and fed the firm's dashboard for assessing the effectiveness of the DRS. Second, while items from validated scales would have been preferred, some have argued 
that such survey items-typically developed in a context different from the one in which they are ultimately employed-often create "frame-of-reference" problems (Hunter and Pil 1995). As in previous studies that make use of study-specific survey items (e.g., Bidwell 2009; Litwin 2011), we can at least be more assured that survey respondents understood the questions they were being asked and the situational context to which the questions were referring.

A separate issue that comes into play is that of nonrandom sample attrition. Specifically, given the design of the data set and what theory tells us about DRSs, it is possible that some workers reacted to the new system "with their feet." That is, they exited the work situation rather than staying in the organization and revealing changes in their perceptions of justice. To the extent that those most likely to sense injustice or those least committed to the organization were more likely to leave the organization, their absence in the post-DRS period could bias the estimated effects of the DRS. Note that we do not try to decompose the DRS's ability to "change minds" from its instrumentality over the composition of the workforce. Rather, we demonstrate changes in within-store workforce means in the dependent variables over the sample period. Nonetheless, one can re-run all of the analyses in the article on the subset of respondents in the post-DRS period that were reportedly working for Gilda's in the pre-DRS period. ${ }^{8}$ Indeed, when we do, all of the estimates run on this limited data set are qualitatively identical to the ones run on the full data set and presented above.

Finally, while our models are careful to control for time-constant, unobserved factors at the store level, the nature of the "treatment"-putting the DRS into effect-does not allow for an econometric means by which to fully control for time-varying drivers at the store level. This control would be feasible only if the DRS itself went into effect at varying times in different stores, allowing us to partial out the impact of unobserved variables, be they spatial or temporal, using an event study-type framework (McWilliams and Siegel 1997). Therefore, we must rely on our own observation as well as consistent reports from Gilda's HR professionals and managers that there were no systematic changes in the work environment within stores over the observation period. Indeed, as noted above, the richness of this qualitative information is what made the research setting so appealing despite the aforementioned challenges that it creates for generalizability.

\section{Conclusion}

This study exploited unique, longitudinal data from a single company, allowing us to evaluate employee perceptions of organizational justice and beliefs about whether and to what extent the firm implementing the DRS is complying with the law, both before and after its implementation. Findings from the case suggest that implementing a DRS has the theorized differential

${ }^{8}$ The survey asks employees to self-report how many years they have been Gilda's employees. 
effects on organizational justice. In the data analyzed, the effects of DRS implementation are decreased procedural justice and increased interactional justice and increased perceived legal compliance. Implementation of Gilda's DRS has no statistically significant effect on organizational commitment. These findings raise important questions about the degree to which commitment to remain employed at a firm is associated with unilaterally imposed DRSs in a nonunion environment, implying that perhaps part of the fundamental trade-off of formal voice procedures like mandatory arbitration is increased perceived legal compliance for reduced perceived procedural justice, with no net effect on organizational commitment. Perhaps the corresponding increase in interactional justice associated with the DRS's implementation is linked to employee commitment, but commitment to local supervisors - what could be described as interpersonal commitmentinstead of to the organization.

To explain these findings, we offer the differential effects model linking employment dispute resolution with organizational justice, organizational commitment, interpersonal commitment, and perceived legal compliance as a means of sparking conversations about the relationship among these important constructs. We hope to cast some doubt on the unidirectional, standard model of DRS implementation. As noted above, we do not set out to fully test the differential effects model we propose. It is offered to augment our understanding of the relationship among these constructs built on decades of research and to push future research in more productive directions. In addition to advancing theory, dispute system design might benefit from contemplating how to plan for an environment of diminished trust in centralized management or in the firm itself as the cost of augmented trust in localized management. Is such a trade-off avoidable? Is it possible to flip in the other direction-augmented, global, organizational trust in exchange for decreased, localized trust for effective and fair dispute resolution? Finally, this research raises important questions about the relationship between organizational commitment and procedural justice. These and other questions emerging from this study deserve continued attention given the vast number of organizations contemplating implementation of a DRS, often without knowledge of the trade-offs this study uncovers.

\section{References}

Ambrose, Maureen L., and Marshall Schminke. 2003. Organization structure as a moderator of the relationship between procedural justice, interactional justice, perceived organizational support, and supervisory trust. Journal of Applied Psychology 88:295-305.

Aquino, Karl, Margaret U. Lewis, and Murray Bradfield. 1999. Justice constructs, negative affectivity, and employee deviance: A proposed model and empirical test. Journal of Organizational Behavior 20:1073-91.

Aquino, Karl, T. M. Tripp, and R. J. Bies. 2006. Getting even or moving on: Power, procedural justice, and types of offense as predictors of revenge, forgiveness, reconciliation, and avoidance in organizations. Journal of Applied Psychology 91:653-68.

Aram, John D., and Paul F. Salipante, Jr. 1981. An evaluation of organizational due process in the resolution of employee/employer conflict. Academy of Management Review 6:197-204. 
Balser, Deborah B. 2000. Perceptions of on-the-job discrimination and employees with disabilities. Employee Responsibilities and Rights Journal 12:179-97.

Baltagi, Badi H. 2005. Econometric Analysis of Panel Data. Chichester, NY: John Wiley.

Batt, Rosemary, Alexander J. S. Colvin, and Jeffrey Keefe. 2002. Employee voice, human resource practices, and quit rates: Evidence from the telecommunications industry. Industrial E Labor Relations Review 55:573-94.

Becker, T. E., R. S. Billings, D. M. Eveleth, and N. L. Gilbert. 1996. Foci and bases of employee commitment: Implications for job performance. Academy of Management Journal 39:464-82.

Bendersky, Corrine. 2003. Organizational dispute resolution systems: A complementarities model. Academy of Management Review 28:643-56.

Bertrand, Marianne, Esther Duflo, and Sendhil Mullainathan. 2004. How much should we trust difference-in-differences estimates? Quarterly Journal of Economics 119:249-75.

Bidwell, Matthew. 2009. Do peripheral workers do peripheral work? Comparing the use of highly-skilled contractors and regular employees. Industrial Eं Labor Relations Review 62:20025.

Bies, Robert J. 2001. Interactional (in)justice: The sacred and the profane. In J. Greenberg and R. Cropanzano (Eds.), Advances in Organizational Justice. Stanford, CA: Stanford University Press.

Bies, Robert J., and Joseph F. Moag. 1986. Interactional justice: Communication criteria of fairness. In R. J. Lewicki, B. H. Sheppard, and M. H. Bazerman (Eds.), Research on Negotiations in Organizations, Vol. 1, pp. 43-55. Greenwich, CT: JAI Press.

Bies, Robert J., and Tom R. Tyler. 1993. The "litigation mentality" in organizations: A test of alternative psychological explanations. Organization Science 4:352-66.

Blancero, Donna Maria, Robert G. DelCampo, and George F. Marron. 2010. Just tell me! Making alternative dispute resolution systems fair. Industrial Relations: A Journal of Economy and Society 49:524-43.

Boroff, Karen E. 1991. Measuring the perceptions of the effectiveness of a workplace complaint system. In Donna Sockell, David Lewin, and David B. Lipsky (Eds.), Advances in Industrial Relations, Vol. 5, pp. 207-33. Greenwich, CT: JAI Press.

Boroff, Karen E., and David Lewin. 1997. Loyalty, voice, and intent to exit a union firm: A conceptual and empirical analysis. Industrial and Labor Relations Review 51:50-63.

Budd, John W. 2004. Employment with a Human Face: Balancing Efficiency, Equity, and Voice. Ithaca, NY: Cornell University Press/ILR Press.

Budd, John W., and Alexander J. S. Colvin. 2008. Improved metrics for workplace dispute resolution procedures: Efficiency, equity, and voice. Industrial Relations: A Journal of Economy and Society 47:460-79.

Byrne, Zinta. 2005. Fairness reduces the negative effects of organizational politics on turnover intentions, citizenship behavior and job performance. Journal of Business and Psychology 20:175-200.

Clegg, H. A. 1975. Pluralism in industrial relations. British Journal of Industrial Relations 13:309-16.

Cohen-Charash, Yochi, and Paul E. Spector. 2001. The role of justice in organizations: A meta-analysis. Organizational Behavior and Human Decision Processes 86:278-321.

Colquitt, Jason A. 2001. On the dimensionality of organizational justice: A construct validation of a measure. Journal of Applied Psychology 86:386-400.

Colquitt, Jason A., Donald E. Conlon, Michael J. Wesson, Christopher O. L. H. Porter, and K. Yee Ng. 2001. Justice at the millennium: A meta-analytic review of 25 years of organizational justice research. Journal of Applied Psychology 86:425-45.

Colquitt, Jason A., Raymond A. Noe, and Christine L. Jackson. 2002. Justice in teams: Antecedents and consequences of procedural justice climate. Personnel Psychology 55:83-109.

Colvin, Alexander J. S. 2003. Institutional pressures, human resource strategies, and the rise of nonunion dispute resolution procedures. Industrial and Labor Relations Review 56:375-92. 2004. Adoption and use of dispute resolution procedures in the nonunion workplace. Advances in Industrial and Labor Relations 13:71-97.

- 2011. An empirical study of employment arbitration: Case outcomes and processes. Journal of Empirical Legal Studies 8:1-23. 
Colvin, Alexander J. S., Brian Klaas, and Douglas Mahony. 2006. Research on alternative dispute resolution procedures. In David Lewin (Ed.), Contemporary Issues in Employment Relations, pp. 103-47. Champaign, IL: Labor and Employment Relations Association.

Cook, J., and T. D. Wall. 1980. New work attitude measures of trust, organizational commitment and personal need for non-fulfillment. Journal of Occupational Psychology 53:39-52.

Cropanzano, Russell, Cynthia A. Prehar, and Peter Y. Chen. 2002. Using social exchange theory to distinguish procedural from interactional justice. Group E Organization Management 27:324-51.

Detert, James R., and Linda K. Trevino. 2010. Speaking up to the higher-ups: How supervisors and skip-level leaders influence employee voice. Organization Science 21:249-70.

Edwards, Paul K., and Hugh Scullion. 1982. The Social Organization of Industrial Conflict: Control and Resistance in the Workplace. Oxford: Blackwell.

Eigen, Zev J. 2008. The devil in the details: The interrelationship among citizenship, rule of law and form-adhesive contracts. Connecticut Law Review 41:1-50.

Eigen, Zev J., Nicholas Menillo, and David S. Sherwyn. 2012. Shifting the paradigm of the debate: A proposal to eliminate at-will employment and implement a "mandatory arbitration act." Indiana Law Journal 87:271-88.

Estreicher, Samuel, and Zev J. Eigen. 2010. The forum for adjudication of employment disputes. In M. L. Wachter and C. L. Estlund (Eds.), Research Handbook on the Economics of Labor and Employment Law. Edward Elgar Publishing Ltd.

Ewing, David W. 1989. Justice on the Job: Resolving Grievances in the Nonunion Workplace: Boston: Harvard Business School Press.

Feldman, Yuval, and Tom R. Tyler. 2012. Mandated justice: The potential promise and possible pitfalls of mandating procedural justice in the workplace. Regulation E Governance 6:4665.

Folger, Robert. 1977. Distributive and procedural justice: Combined impact of "voice" and improvement on experienced inequity. Journal of Personality and Social Psychology 35:108-19.

1993. Reactions to mistreatment at work. In J. Keith Murnighan (Ed.), Social Psychology in Organizations: Advances in Theory and Research, pp. 161-83. Upper Saddle River, NJ: Prentice Hall.

Folger, Robert, and Robert J. Bies. 1989. Managerial responsibilities and procedural justice. Employee Responsibilities and Rights Journal 2:79-90.

Folger, Robert, and Mary A. Konovsky. 1989. Effects of procedural and distributive justice on reactions to pay raise decisions. Academy of Management Journal 32:115-30.

Fryxell, Gerald E., and Michael E. Gordon. 1989. Workplace justice and job satisfaction as predictors of satisfaction with union and management. Academy of Management Journal 32:851-66.

Gilbert, Jacqueline A., and Tang Thomas Li-Ping. 1998. An examination of organizational trust antecedents. Public Personnel Management 27:321.

Gopinath, C., and Thomas E. Becker. 2000. Communication, procedural justice, and employee attitudes: relationships under conditions of divestiture. Journal of Management 26:6383.

Greenberg, Jerald. 1990. Employee theft as a reaction to underpayment equity: The hidden costs of paycuts. Journal of Applied Psychology 75:561-68.

. 1993. Stealing in the name of justice: Informational and interpersonal moderators of theft reactions to underpayment inequity. Organizational Behavior and Human Decision Processes 54:81-103.

Greenberg, Jerald S., and Russell S. Cropanzano. 2001. Advances in Organizational Justice. Palo Alto, CA: Stanford University Press.

Greenberg, Liane, and Julian Barling. 1996. Employee theft. In C. L. Cooper and D. M. Rousseau (Eds.), Trends in Organizational Behavior, Vol. 3, pp. 49-64. Hoboken, NJ: John Wiley \& Sons.

Gregersen, Hal B., and J. Stewart Black. 1992. Antecedents to commitment to a parent company and a foreign operation. Academy of Management Journal 35:65-71.

Hirschman, Albert O. 1970. Exit, Voice and Loyalty. Cambridge, MA: Harvard University Press. Hubbell, Anne P., and Rebecca M. Chory-Assad. 2005. Motivating factors: Perceptions of 
justice and their relationship with managerial and organizational trust. Communication Studies 56:47-70.

Hunter, Larry W., and Frits K. Pil. 1995. How do you survey firms? In Paula B. Voos (Ed.), Proceedings of the 47th Annual Meeting of the Industrial Relations Research Association, pp. 152-62. Madison, WI: IRRA.

Ichniowski, Casey. 1986. The effects of grievance activity on productivity. Industrial E Labor Relations Review 40:75-89.

Klaas, Brian S., Julie B. Olson-Buchanan, and Anna-Katherine Ward. 2012. The determinants of alternative forms of workplace voice. Journal of Management 38:314-45.

Konovsky, Mary A., and Robert Folger. 1991. The effects of procedures, social accounts, and benefits level on victims' layoff reactions. Journal of Applied Social Psychology 21:630-50.

Lewin, David. 1987. Dispute resolution in the nonunion firm: A Theoretical and empirical analysis. Journal of Conflict Resolution 31:465-502.

Lewin, David, and Richard B. Peterson. 1999. Behavioral outcomes of grievance activity. Industrial Relations 38:554.

Lind, E. Allan, and Tom R. Tyler. 1988. The Social Psychology of Procedural Justice. New York: Plenum.

Lipsky, David B., and Ronald L. Seeber. 2006. Managing organizational conflicts. In John G. Oetzel and Stella Ting-Toomey (Eds.), The Sage Handbook of Conflict Communication: Integrating Theory, Research, and Practice, pp. 359-90. Thousand Oaks, CA: Sage Publications.

Lipsky, David B., Ronald L. Seeber, and Richard D. Fincher. 2003. Emerging Systems for Managing Workplace Conflict: Lessons from American Corporations for Managers and Dispute Resolution Professionals. San Francisco: Jossey-Bass.

Litwin, Adam Seth. 2011. Technological change at work: The impact of employee involvement on the effectiveness of health information technology. Industrial E Labor Relations Review 64:863-88.

Mahony, Douglas, and Brian Klaas. 2008. Comparative dispute resolution in the workplace. Journal of Labor Research 29:251-71.

Masterson, Suzanne S., Kyle Lewis, Barry M. Goldman, and M. Susan Taylor. 2000. Integrating justice and social exchange: The differing effects of fair procedures and treatment on work relationships. Academy of Management Journal 43:738-48.

McCabe, Douglas M., and David Lewin. 1992. Employee voice: A human resource management perspective. California Management Review 34:112-23.

McFarlin, Dean B., and Paul D. Sweeney. 1992. Distributive and procedural justice as predictors of satisfaction with personal and organizational outcomes. Academy of Management Journal 35:626-37.

McWilliams, Abigail, and Donald Siegel. 1997. Event studies in management research: Theoretical and empirical issues. Academy of Management Journal 40:626-57.

Moorman, Robert H. 1991. Relationship between organizational justice and organizational citizenship behaviors: Do fairness perceptions influence employee citizenship? Journal of Applied Psychology 76:845-55.

Moorman, Robert H., Brian P. Niehoff, and Dennis W. Organ. 1993. Treating employees fairly and organizational citizenship behavior: Sorting the effects of job satisfaction, organizational commitment, and procedural justice. Employee Responsibilities and Rights Journal 6:209-25.

Mowday, Richard T., Richard M. Steers, and Lyman W. Porter. 1979. The measurement of organizational commitment. Journal of Vocational Behavior 14:224-47.

Naumann, Stefanie E., and Nathan Bennett. 2000. A case for procedural justice climate: Development and test of a multilevel model. Academy of Management Journal 43:881-89.

Niehoff, Brian P., and Robert H. Moorman. 1993. Justice as a mediator of the relationship between methods of monitoring and organizational citizenship behavior. Academy of Management Journal 36:527-56.

Ruppel, Cynthia P., and Susan J. Harrington. 2000. The relationship of communication, ethical work climate and trust to commitment and innovation. Journal of Business Ethics 25:313-28.

Schwab, Donald P. 2005. Research Methods for Organizational Studies. Mahwah, NJ: Lawrence Erlbaum Associates. 
Schwartz, David S. 2009. Mandatory arbitration and fairness. Notre Dame Law Review 84:12471341.

Sheppard, Blair H., Roy J. Lewicki, and John W. Minton. 1992. Organizational Justice. New York: Lexington Books.

Sherwyn, David S., Samuel Estreicher, and Michael Heise. 2005. Assessing the case for employment arbitration: A new path for empirical research. Stanford Law Review 57:1557-91.

Singer, Judith D., and John B. Willett. 2003. Applied Longitudinal Data Analysis: Modeling Change and Event Occurrence. New York: Oxford University Press.

Skrondal, Anders, and Sohia Rabe-Hesketh. 2004. Generalized Latent Variable Modeling: Multilevel, Longitudinal, and Structural Equation Models. Boca Raton, FL: Chapman and Hall/CRC.

Spencer, Daniel G. 1986. Employee voice and employee retention. Academy of Management Journal 29:488-502.

Stone, Katherine V. W. 1996. Mandatory arbitration of individual employment rights: The yellow dog contract of the 1990s. University of Denver Law Review 73:1017.

Sweeney, Paul D., and Dean B. McFarlin. 1993. Workers' evaluations of the "ends" and the "means": An examination of four models of distributive and procedural justice. Organizational Behavior and Human Decision Processes 55:23-40.

Thibaut, John L., and Laurens Walker. 1975. Procedural Justice: A Psychological Analysis. Hillsdale, NJ: Lawrence Erlbaum Associates.

Tyler, Tom R. 1988. What is procedural justice? Criteria used by citizens to assess the fairness of legal procedures. Law E Society Review 22:103-35.

. 2006. Why People Obey the Law. Princeton, NJ: Princeton University Press.

Tyler, Tom R., and Robert J. Bies. 1988. Beyond Formal Procedures: The International Context of Procedural Justice. Evanston, IL: Kellogg Graduate School of Management, Northwestern University.

1990. Beyond formal procedures: The interpersonal context of procedural justice. In John S. Carroll (Ed.), Applied Psychology and Organizational Settings, pp. 77-98. Hillsdale, NJ: Lawrence Erlbaum Associates.

Tyler, Tom R., and Steven L. Blader. 2000. Cooperation in Groups: Procedural Justice, Social Identity, and Behavioral Engagement. Philadelphia, PA: Psychology Press.

Wallace, J. Craig, Bryan D. Edwards, Scott P. Mondore, and David M. Finch. 2008. Employee discrimination claims and employee-initiated lawsuits: Does procedural justice climate moderate the claims $\rightarrow$ disputes relationship? Journal of Managerial Issues 20:313-26.

Whitener, Ellen M. 2001. Do "high commitment" human resource practices affect employee commitment? Journal of Management 27:515-35.

Zack, Arnold M. 1999. Agreements to arbitrate and the waiver of rights under employment law. In Adrienne E. Eaton and Jeffrey H. Keefe (Eds.), Employment Dispute Resolution and Worker Rights in the Changing Workplace, pp. 67-94. Champaign, IL: Industrial Relations Research Association. 